\title{
LASS2 inhibits proliferation and induces apoptosis in HepG 2 cells by affecting mitochondrial dynamics, the cell cycle and the nuclear factor- $\kappa B$ pathways
}

\author{
YAN YANG ${ }^{1,2}$, XIAOLI YANG ${ }^{1,2}$, LIN LI $^{3}$, GANGYI YANG $^{4}$, XUHONG OUYANG $^{1,2}$, \\ JIALIN XIANG ${ }^{1,2}$, TAO ZHANG ${ }^{1,2}$ and XUN MIN ${ }^{1,2}$ \\ ${ }^{1}$ Department of Clinical Laboratory, Affiliated Hospital of Zunyi Medical University; \\ ${ }^{2}$ College of Laboratory Medicine, Zunyi Medical University, Zunyi, Guizhou 563003; \\ ${ }^{3}$ The Key Laboratory of Medical Diagnostics in the Ministry of Education and \\ Department of Clinical Biochemistry, College of Laboratory Medicine, \\ Chongqing Medical University; ${ }^{4}$ Department of Endocrinology, \\ The Second Affiliated Hospital, Chongqing Medical University, \\ Chongqing, Sichuan 400010, P.R. China
}

Received August 12,2018; Accepted March 7, 2019

DOI: $10.3892 / o r .2019 .7058$

\begin{abstract}
LAG1 longevity assurance homolog 2 (LASS2) is a candidate biomarker in cancer that is dysregulated in various types of tumor, potentially affecting cell growth, invasion and migration. Although its effects on liver cancer metastasis and invasion have been reported, specific phenotypic studies and potential molecular mechanisms have not been completely elucidated in hepatoblastoma (HB). In the present study, the effect of LASS2 on the proliferation, apoptosis and cell cycle of HepG2 HB cells was assessed, and the underlying mechanisms were investigated. The human LASS2 coding sequence was inserted into an adenovirus vector and transduced into HepG2 cells. It was determined that the overexpression of LASS2 inhibited HepG2 cell viability and proliferation, as determined by cell counting kit-8 and colony formation assays, and induced apoptosis by increasing reactive oxygen species, reducing mitochondrial membrane potential and inducing intracellular $\mathrm{Ca}^{2+}$ overload. In addition, the overexpression of LASS2 induced $\mathrm{G}_{0} / \mathrm{G}_{1}$ cell cycle arrest through modulating the expression of cell cycle regulatory proteins, including p27, cyclin D1 and cyclin-dependent kinase 4. Immunofluorescence was used to determine that nuclear factor (NF)- $\mathrm{B}$ p-p65 was primarily expressed in the cytoplasm rather than in the nucleus; western blot analysis demonstrated that LASS2
\end{abstract}

Correspondence to: Professor Xun Min, Department of Clinical Laboratory, Affiliated Hospital of Zunyi Medical University, 149 Dalian Road, Zunyi, Guizhou 563003, P.R. China

E-mail: yy623yy@163.com; xunmin10zy@sina.com

Key words: LAG1 longevity assurance homolog 2, hepatoblastoma, HepG2, cell apoptosis, proliferation, cell cycle downregulated the expression of NF- $\kappa \mathrm{B}$ p-p65 relative to its inactive form in HepG2 cells. These findings suggest that LASS2 inhibits proliferation and induces apoptosis in HepG2 $\mathrm{HB}$ cells through the mitochondrial apoptotic, NF- $\mathrm{kB}$ and cell cycle signaling pathways.

\section{Introduction}

Liver cancer is the second most common cause of cancer-associated fatality worldwide, and is one of the few types of neoplasm with a steadily increasing incidence and mortality (1-3). Liver cancer subtypes include hepatocellular carcinoma (HCC), intrahepatic cholangiocarcinoma, mixed hepatocellular cholangiocarcinoma (HCC-CCA) and rarer types, such as hepatoblastoma (HB) (4). HB is the most common pediatric malignant liver cancer (5). Although the survival rate for HB has increased from $\sim 30$ to $>80 \%$ with the application of surgical resection, chemotherapy and liver transplantation (6), the molecular development of this aggressive embryonal tumor remains largely uncharacterized (7). Further research regarding the underlying molecular mechanisms will aid to improve the diagnosis and treatment of patients with HB.

Human LAG1 longevity assurance homolog 2 (LASS2), also known as ceramide synthase 2 or tumor metastasis suppressor gene 1 , is a $45-\mathrm{kDa}$ membrane protein (8). The expression of LAG1 longevity assurance homolog 2 (LASS2) protein is primarily confined to the nuclear and endoplasmic reticular membranes (9). A previous study demonstrated that LASS 2 knockout induced autophagy and the unfolded protein response, through its participation in the regulation of endoplasmic reticulum stress (10). As a recently identified tumor suppressor gene, LASS2 may also serve an important role in inhibiting the invasion and metastasis of various types of tumor (11-16). The silencing of LASS2 enhances 
the growth, invasion and migration of $\operatorname{HCC}(11,12)$, bladder cancer $(13,14)$, breast cancer $(8,15)$ and prostate cancer $(16)$ cells by regulating ATPase activity. In addition, the reduced tumor expression of LASS2 protein was identified to be associated with a worse prognosis in patients with meningioma (17); LASS2 tumor expression was also observed to be negatively correlated with tumor size, tumor differentiation and TNM stage in patients with HCC (18). Although its effects on HCC metastasis and invasion have been reported, to the best of our knowledge, the precise role of LASS2 in tumorigenesis and its potential effects on HB cell proliferation, apoptosis and cell cycle in vitro have yet to be investigated. Therefore, the proliferation, apoptosis and cell cycle-associated nuclear factor (NF)- $\mathrm{B}$ p65/p27/cyclin D1/cyclin-dependent kinase 4 (CDK4) signaling pathway were considered to explore the potential role of LASS2 in the tumorigenesis of human HB.

\section{Materials and methods}

$A d v$-LASS2-green fluorescent protein (GFP) recombinant adenovirus vector construction. To construct the recombinant adenovirus vector Adv-LASS2-GFP, the LASS2-GFP (human LASS2 coding sequence, NM_022075; 627 ng/ $\mu \mathrm{l})$ and the pShuttle-CMV recombinant shuttle vector (BAC Biological Technology Co., Ltd., Beijing, China) were digested with HindIII and NotI (New England Biolabs, Inc., Ipswich, MA, USA). The digested vector and insert segments were ligated with T4 DNA ligase. Transformation, plasmid mini-extraction and sequencing were performed to obtain a verified pShuttle-LASS2-GFP recombinant shuttle plasmid. Following this, the pAdxsi vector (BAC Biological Technology Co., Ltd.) and pShuttle-LASS2-GFP were separately digested with I-CeuI and I-SceI, followed by ligation and transformation, to obtain a pAdxsi-LASS2-GFP viral plasmid. Extraction of the viral plasmids was performed, linearized pAdxsi-LASS2-GFP viral plasmid was transfected into 293 cells using Lipofectamine 2000 (Invitrogen; Thermo Fisher Scientific, Inc., Waltham, MA, USA), which was followed by collection and amplification to finally obtain a recombinant Adv-LASS2-GFP with a titer of $1.2 \times 10^{10}$ plaque-forming units/milliliter.

Cell culture and transfection. Human HB HepG2 cells (19) were kindly provided and authenticated using short tandem repeat markers by Stem Cell Bank, Chinese Academy of Sciences (Shanghai, China). It is notable that the HepG2 cells are typically misidentified as a HCC cell line, which is frequently erroneously used in HCC research $(20,21)$.

Cells were cultured in the recommended medium, Dulbecco's modified Eagle's medium (DMEM; Gibco; Thermo Fisher Scientific, Inc.), supplemented with $10 \%$ fetal bovine serum (Gibco; Thermo Fisher Scientific, Inc.), $100 \mathrm{U} / \mathrm{ml}$ penicillin and $100 \mathrm{U} / \mathrm{ml}$ streptomycin. Cells were incubated at $37^{\circ} \mathrm{C}$ in a humidified atmosphere containing $5 \% \mathrm{CO}_{2}$. Cells in the exponential phase of growth were counted, seeded in 6-well plates and transfected with the recombinant adenoviruses (Adv-LASS2-GFP or Adv-GFP control) at 50-70\% confluence following 24-h incubation. All assays were performed in triplicate.
Determination of the subcellular localization of LASS2 by confocal laser scanning microscopy. Adv-GFP or Adv-LASS2-GFP vectors were transfected into HepG2 cells that were subsequently incubated for $48 \mathrm{~h}$. Cells were placed on slides, washed three times with phosphate-buffered saline (PBS) and fixed by incubation in $4 \%$ paraformaldehyde for $30 \mathrm{~min}$ at room temperature. The nuclei were stained with 4',6-diamidino-2-phenylindole (DAPI) in the dark for $5 \mathrm{~min}$ at room temperature and washed three times. A confocal microscope (LSM710; Carl Zeiss AG, Oberkochen, Germany) was used to analyze the expression of the GFP-LASS2 protein, which was detected with the GFP filter at $525 \mathrm{~nm}$, following excitation at $488 \mathrm{~nm}$. The cell nuclei were identified with laser excitation at $340 \mathrm{~nm}$ and emission at $488 \mathrm{~nm}$. Images were acquired at x200 magnification.

Cell counting kit-8 (CCK-8) cell viability assay. Cell viability and cell number were assessed using a CCK-8 assay (Beyotime Institute of Biotechnology, Shanghai, China). HepG2 cells were seeded into 96 -well plates at $10^{4}$ cells/well. pAdv-GFP or pAdv-LASS2-GFP vectors were transfected into the cells, which were subsequently incubated for $0,24,48,72$ or $96 \mathrm{~h}$. The cells were incubated with $10 \mu \mathrm{lCCK}-8$ solution for $1 \mathrm{~h}$. The optical density (OD) was measured at $450 \mathrm{~nm}$. The cell proliferation rate $(\%)=(\mathrm{OD}$ value of the test well $-\mathrm{OD}$ value of the background control well) / (OD value of the control well - OD value of the background control) x $100 \%$.

Colony formation assay. The transfected cells were collected and seeded in $6-\mathrm{cm}$ sterile petri dishes at a density of $10^{3}$ cells/well. At 14 days from the initial appearance of colonies, the cells were washed twice with PBS, fixed with $4 \%$ paraformaldehyde for $20 \mathrm{~min}$ at room temperature and stained with crystal violet for $20 \mathrm{~min}$ at room temperature. Subsequently, the number of colonies ( $\geq 50$ cells) was determined.

Cell cycle analysis. HepG2 cells were transfected with Adv-GFP or Adv-LASS2-GFP for $48 \mathrm{~h}$. Subsequently, the cells were harvested, washed with PBS and prepared into single-cell suspension $\left(10^{6} \mathrm{cell} / \mathrm{s} / \mathrm{ml}, 1 \mathrm{ml} /\right.$ group $)$. The precipitate was removed by centrifugation at $800 \mathrm{x}$ g for $5 \mathrm{~min}$ at room temperature and the cells fixed in $500 \mu 170 \%$ ice-cold ethanol for $2 \mathrm{~h}$, or overnight. Following this, cells were incubated with $100 \mu \mathrm{l}$ RNAase at $37^{\circ} \mathrm{C}$ for $30 \mathrm{~min}$ and stained with $400 \mu \mathrm{l}$ propidium iodide (Nanjing KeyGen Biotech, Nanjing, China) for $30 \mathrm{~min}$ at $4^{\circ} \mathrm{C}$ while protected from light. The stained cells were subjected to flow cytometry using a flow cytometer (FACSCalibur; BD Biosciences, San Jose, CA, USA) and the proportion of cells phases in $G_{0} / G_{1}, S$ and $G_{2} / M$ were analyzed using ModFit software (version 3.3; Verity Software House, Inc., Topsham, ME, USA).

Annexin V-allophycocyanin (APC)/7-amino-actinomycin D (7-AAD) double staining apoptosis assay. Transfected HepG2 cells were harvested with $0.25 \%$ trypsin without EDTA, washed twice with cold PBS and resuspended in $500 \mu \mathrm{l}$ binding buffer. Following this, $5 \mu \mathrm{l}$ Annexin V-APC and $5 \mu \mathrm{l}$ 7-AAD (Nanjing KeyGen Biotech) were added in sequence according to the manufacturer's protocol. Cells were incubated 
for $15 \mathrm{~min}$ at room temperature while protected from light, then immediately analyzed using flow cytometry as described above and CellQuest software 6.0 (BD Biosciences).

Terminal deoxynucleotidyl transferase dUTP nick end labeling (TUNEL) assay. Apoptosis-associated nuclear DNA fragmentation was detected using a commercial biotin dUTP-labeling TUNEL kit (cat. no. KGA702; KeyGen Biotech) according to the manufacturer's instructions. Briefly, HepG2 cells were seeded onto slides in 6-well plates. Following $48 \mathrm{~h}$ of incubation, the slides were dried and washed with PBS three times. Cells were fixed with $4 \%$ paraformaldehyde for $30 \mathrm{~min}$ at room temperature and permeabilized with $1 \%$ Triton $\mathrm{X}-100$. Subsequently, cells were incubated in $3 \% \mathrm{H}_{2} \mathrm{O}_{2}$ in methanol for $10 \mathrm{~min}$ at room temperature to block endogenous peroxidase activity, washed in PBS and incubated with a mixture of TdT and fluorescein isothiocyanate dUTP solutions in a humidified chamber at $37^{\circ} \mathrm{C}$ for $60 \mathrm{~min}$. This was followed by washing in PBS and incubated with streptavidin-conjugated horseradish peroxidase (dilution, 1:100; from the TUNEL kit) in a humidified chamber at $37^{\circ} \mathrm{C}$ for $30 \mathrm{~min}$. When cells were washed with PBS, DAPI solution was applied, followed by counterstaining with hematoxylin. The dehydrated sections were cleared in xylene, mounted with neutral balsam and enclosed with coverslips. Over 200 cells with brown granules in the nuclei were considered to be TUNEL-positive. Cells were assessed in at least three high-powered fields of view (magnification, x200) under an optical microscope (Olympus Corporation, Tokyo, Japan) to determine the mean percentage of positive cells.

Intracellular reactive oxygen species (ROS) measurement. Intracellular ROS were monitored using dihydroethidium (DHE; Nanjing KeyGen Biotech) as the probe. HepG2 cells were trypsinized, washed with PBS and resuspended in $1 \mathrm{ml}$ serum-free medium supplemented with $10 \mu \mathrm{M}$ DHE at density of $1 \times 10^{6} / \mathrm{ml}$ following transfection. Cells were incubated at $37^{\circ} \mathrm{C}$ for $20 \mathrm{~min}$ in the dark and inverted every $3-5 \mathrm{~min}$ to maximize the contact between the probe and cells. Following this, cells were washed three times with serum-free medium to remove excess DHE. Cellular ROS were subsequently measured using flow cytometry, and fluorescence was read using a fluorescence spectrometer with a $488 \mathrm{~nm}$ excitation and $605 \mathrm{~nm}$ emission wavelength.

Mitochondrial membrane potential $(\Delta \Psi \mathrm{m})$ assays. $\Delta \Psi \mathrm{m}$ was measured using the JC-1 apoptosis detection kit (Nanjing KeyGen Biotech). Briefly, HepG2 cells transfected with the Adv-GFP or Adv-LASS2-GFP vectors were incubated for 48 h. Cells were collected, washed with PBS, resuspended in $500 \mu \mathrm{l} \mathrm{JC}-1$ working solution and incubated at $37^{\circ} \mathrm{C}$ with $5 \% \mathrm{CO}_{2}$ for $20 \mathrm{~min}$. Cells were collected by centrifugation ( $800 \mathrm{x} \mathrm{g}$ for $5 \mathrm{~min}$ at room temperature), washed twice with $1 \mathrm{X}$ incubation buffer and resuspended in $500 \mu \mathrm{l} 1 \mathrm{X}$ incubation buffer. The concentration of retained JC-1 dye was determined by flow cytometry with an excitation wavelength of $488 \mathrm{~nm}$ and an emission wavelength of $530 \mathrm{~nm}$.

$\mathrm{Ca}^{2+}$-ATPase assays. ATPases decompose ATP to produce ADP and inorganic phosphate (22). Therefore, $\mathrm{Ca}^{2+}$-ATPase activity was determined using a colorimetric method to detect the inorganic phosphate content. Transfected cells were digested and centrifuged as described above. A total of $500 \mu \mathrm{l}$ cell suspension was added to each tube to a density of $10^{6}$ cells $/ \mathrm{ml}$. The cells were disrupted by ultrasonic homogenization. The detection of inorganic phosphate was performed with the Ultra Trace $\mathrm{Ca}^{2+}$-ATPase assay kit (Nanjing KeyGen Biotech) according to the manufacturer's instructions.

Intracellular $\mathrm{Ca}^{2+}$ concentration $\left[\mathrm{Ca}^{2+}\right]_{i}$ determination . Transfected cells were washed twice with PBS and a single-cell suspension was prepared by centrifugation of $10^{6} \mathrm{cell} / \mathrm{s} / \mathrm{ml}$ at $800 \mathrm{~g}$ for $5 \mathrm{~min}$. Calbryte 630 AM (AAT Bioquest, Inc., Sunnyvale, CA, USA) was dissolved in dimethyl sulfoxide to prepare a $2 \mathrm{mM}$ stock solution; a working solution of $20 \mu \mathrm{M}$ Calbryte 630 AM in Hank's balanced salt solution was also prepared. A total of $500 \mu \mathrm{l}$ Calbryte $630 \mathrm{AM}$ working solution was added into each well, and the dye-loaded plate was incubated for $60 \mathrm{~min}$, followed by incubation at room temperature in the dark for a further $15 \mathrm{~min}$. Cells were collected by centrifugation at $800 \mathrm{x} \mathrm{g}$ for $5 \mathrm{~min}$ at room temperature, and washed twice with 1X Hank's buffer with HEPES (HHBS) to remove excess dye. Cells were resuspended in $500 \mu 1$ 1X HHBS and analyzed using flow cytometry for Calbryte 630 AM content, with an excitation wavelength of $610 \mathrm{~nm}$ and an emission wavelength of $640 \mathrm{~nm}$, to determine the $\left[\mathrm{Ca}^{2+}\right]_{\mathrm{i}}$.

Reverse transcription-quantitative polymerase chain reaction (RT-qPCR) analysis. Total RNA was isolated from HepG2 cells using the RNAiso Plus reagent (Takara Bio Inc., Otsu, Japan). cDNA was synthesized using the PrimeScript RT Master Mix kit (Takara Bio Inc.). qPCR was performed with the SYBR Premix Ex Taq II kit (Takara Bio Inc.) and the ABI 7500 Real-Time PCR instrument (Applied Biosystems; Thermo Fisher Scientific, Inc.) according to the manufacturer's instructions. The thermocycling conditions used with the ABI7500 detection system were as follows: $95^{\circ} \mathrm{C}$ for $30 \mathrm{sec}$, followed by 40 cycles of $95^{\circ} \mathrm{C}$ for $5 \mathrm{sec}$ and $60^{\circ} \mathrm{C}$ for $34 \mathrm{sec}$. Relative quantification was performed using the comparative $\mathrm{Cq}\left(2^{-\Delta \Delta \mathrm{Cq}}\right)$ method (23). All data were normalized to the internal control, GAPDH. The specific primers for human LASS2 and GAPDH used in the present study were as follows: GAPDH, sense 5'-GGAGCGAGATCCCTCCAAAAT-3' and antisense 5'-GGCTGTTGTCATACTTCTCATGG-3' (197 bp product); and LASS2, sense 5'-ATCGTCTTCGCCATTGTT-3' and antisense 5'-CGGTCACTGCGTTCATCT-3' (233 bp product).

Immunofluorescence. Cells were cultured on glass coverslips and transfected for $48 \mathrm{~h}$, washed with PBS for $5 \mathrm{~min}$, fixed with $4 \%$ pre-cooled paraformaldehyde for $20 \mathrm{~min}$, washed in PBS three times for 5 min each time and incubated with PBS containing 0.1\% Triton X-100 (Sigma-Aldrich; Merck $\mathrm{KGaA}$, Darmstadt, Germany) on ice for $10 \mathrm{~min}$. Two drops of $3 \% \mathrm{H}_{2} \mathrm{O}_{2}$-methanol solution were added onto each coverslip for $10 \mathrm{~min}$ at room temperature to inactivate endogenous peroxidase, followed by washing three times with PBS again. Cells were blocked with ready-to-use normal goat serum kit (cat. no. AR0009; Boster Biological Technology, Pleasanton, $\mathrm{CA}$, USA) for $20 \mathrm{~min}$ at $37^{\circ} \mathrm{C}$ and incubated with $50 \mu \mathrm{l}$ rabbit anti-human NF- $\mathrm{B}$ p-p65 (Ser536; dilution, 1:100; 
cat. no. 3033; Cell Signaling Technology, Inc., Danvers, MA, USA) on each coverslip overnight at $4^{\circ} \mathrm{C}$. Following this, cells were incubated with tetramethylrhodamine-conjugated goat anti-rabbit IgG secondary antibodies (dilution, 1:100; cat. no. KGAA99; Nanjing KeyGen Biotech) at $37^{\circ} \mathrm{C}$ in the dark for $1 \mathrm{~h}$. Cells were counterstained with DAPI for $5 \mathrm{~min}$ at room temperature and the coverslips were mounted in fluoroshield with DAPI histology mounting medium (cat. no. F657; Sigma-Aldrich; Merck KGaA) and the slides were scanned under a confocal microscope (LSM710; Carl Zeiss AG).

Western blot analysis. The total protein was extracted from HepG2 cells using a protein extraction kit (Nanjing KeyGen Biotech); protein concentrations were measured using a bicinchoninic acid assay kit (Nanjing KeyGen Biotech) according to the manufacturer's protocols. An equal amount of protein (10 $\mu \mathrm{g}$ per lane) for each group was separated using SDS-PAGE (10\% gels) and electrotransferred onto polyvinylidene fluoride membranes (EMD Millipore, Billerica, MA, USA). The membranes were blocked in $5 \%$ skimmed milk for $2 \mathrm{~h}$ at room temperature and incubated overnight at $4^{\circ} \mathrm{C}$ with the primary antibodies, including GAPDH (dilution, 1:5,000; cat. no. EM1101; Hangzhou HuaAn Biotechnology Co., Ltd., Hangzhou, China), anti-LASS2 (dilution, 1:300; cat. no. ab85567; Abcam, Cambridge, UK), cyclin D1 (dilution, 1:5,000; cat. no. ab137875; Abcam), CDK4 (dilution, 1:2,000; cat. no. ab137675; Abcam), NF- $\kappa B$ p65 (dilution, 1:1,000; cat. no. 8242), NF-кB p-p65 (Ser536; dilution, 1:1,000; cat. no. 3033) and p2 $7^{\text {kipl }}$ (dilution, 1:1,000; cat. no. 2552; all from Cell Signaling Technology, Inc.). The membranes were washed and incubated with the secondary antibody (horseradish peroxidase-conjugated goat anti-rabbit IgG; dilution, 1:4,000; cat. no. 5220-0283; KPL, Milford, MA, USA) at room temperature for $1-2 \mathrm{~h}$. The membranes were washed, developed using enhanced chemiluminescent kit (cat. no. SQ101; EpiZyme, Shanghai, China) and analyzed by densitometry relative to the control gene using Gel-Pro analyzer 4.0 (Media Cybernetics, Inc., Rockville, MD, USA).

Statistical analysis. All statistical analyses were performed with SPSS (version 22.0; IBM Corp., Armonk, NY, USA) and GraphPad Prism (version 7.0; GraphPad Software, Inc., La Jolla, CA, USA) software. Data are expressed as the mean \pm standard deviation of at least three independent experiments. One-way analysis of variance with a least-significant-difference test were used for group comparisons. $\mathrm{P}<0.05$ was considered to indicate a statistically significant difference.

\section{Results}

Overexpression of LASS2 inhibits HepG2 cell proliferation. Adenovirus vectors Adv-GFP (vector control) and Adv-LASS2-GFP were generated and successfully transiently transfected into HepG2 cells. The subcellular localization of the LASS2-GFP fusion protein was identified using confocal laser scanning microscope at $48 \mathrm{~h}$ post-transfection. The LASS2-GFP fusion protein was localized to the nuclear membrane and cytosol (Fig. 1A).
Furthermore, using RT-qPCR, it was identified that the Adv-LASS2-GFP-transfected cells exhibited a significantly greater LASS2 mRNA expression level compared with those transfected with Adv-GFP or negative control (NC) cells (51.62-fold difference; Fig. 1B). The LASS2 protein expression levels were also analyzed by western blot analysis. The increased expression of LASS2 protein was evident in the Adv-LASS2-GFP transfected cells when compared with the Adv-GFP or NC cells (10.55-fold; Fig. 1C).

To determine the effect of LASS2 overexpression on cell proliferation, CCK-8 and colony formation assays were performed. Cell proliferation was significantly decreased at $48 \mathrm{~h}$ post-transfection with Adv-LASS2-GFP when compared with cells transfected with Adv-GFP (Fig. 1D). The overexpression of LASS2 significantly suppressed HepG2 colony formation (Fig. 1E). These results indicate that LASS2 overexpression inhibited the proliferation of HepG2 HB cells.

Overexpression of LASS2 induces $G_{0} / G_{1}$ cell cycle arrest via modulating cell cycle regulatory proteins in $\mathrm{Hep} G 2$ cells. To investigate the role of LASS2 in the regulation of the cell cycle in HepG2 cells, the effect of its overexpression on cell cycle progression was assessed. The cell cycle distribution was analyzed using flow cytometry with propidium iodide. The results indicated in Fig. 2A revealed that the overexpression of LASS2 inhibited the cell cycle progression of HepG 2 cells in the $G_{0} / G_{1}$ phase. In the cells transfected with Adv-LASS2-GFP for $48 \mathrm{~h}$ compared with NC or Adv-GFP groups, the percentage of cells in the $\mathrm{G}_{0} / \mathrm{G}_{1}$ phase was significantly increased to $65.13 \pm 3.07 \%$; the proportion of cells in the $S$ and $G_{2} / M$ phases was reduced, with the cells in $S$ phase significantly decreasing from $46.11 \pm 1.77$ to $33.54 \pm 2.30 \%$ and the cells in the $\mathrm{G} 2 / \mathrm{M}$ phase decreasing from $11.58 \pm 1.39$ to $2.00 \pm 0.84 \%$.

To explore the potential mechanisms for the $\mathrm{G}_{0} / \mathrm{G}_{1}$ cell cycle arrest induced by LASS2 in HepG2 cells, the expression of members of the NF- $\mathrm{kB}$ p65/p2 $7^{\mathrm{kip} 1 / c y c l i n ~ D 1 / C D K 4}$ signaling pathway, associated with the cell cycle and proliferation in cancer cells, were examined using western blot analysis and immunofluorescence (Fig. 2B-E).

$\mathrm{NF}-\kappa \mathrm{B}$ is an inducible transcription factor critical for the expression of a variety of genes that affect inflammation, immunity, apoptosis, cell proliferation $(24,25)$ and the cell cycle $(26,27)$. The present results demonstrated that NF- $\kappa B$ p65 activity was suppressed following Adv-LASS2-GFP transfection (Fig. 2B and C). Immunofluorescence analysis revealed that NF- $\kappa \mathrm{B}$ p-p65 was widely expressed in the cytoplasm, with negative staining in the nuclei (Fig. 2B). Western blot analysis indicated that the relative expression of NF- $\mathrm{KB}$ p-p65 was significantly decreased compared with $\mathrm{NC}$ or Adv-GFP groups (Fig. 2C). Although the relative expression level of inactive NF- $\kappa \mathrm{B}$ p65 was also downregulated, the difference was not statistically significant (Fig. 2C).

CDKs are a family of kinases initially identified for their role in the regulation of the cell cycle (28). CDK4 is a key partner for cyclin D1 in the regulation of cell cycle progression from the $\mathrm{G}_{1}$ phase (28). The western blot analysis results indicated that the relative expression of cyclin D1 and CDK4 
A
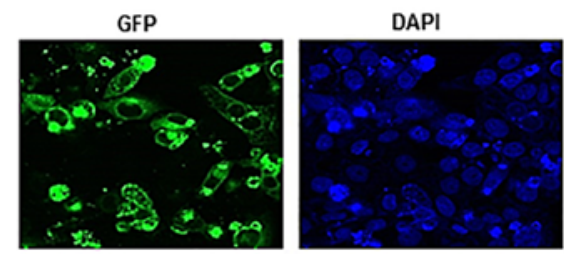

Adv-LASS2-GFP

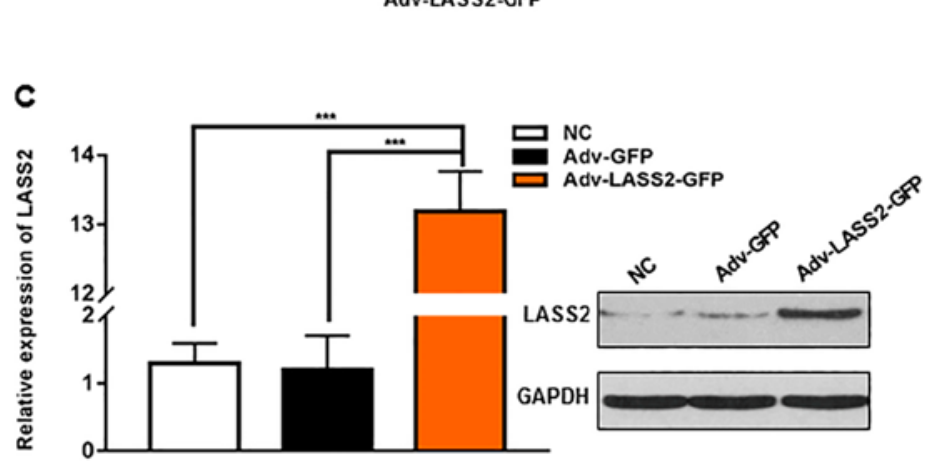

E

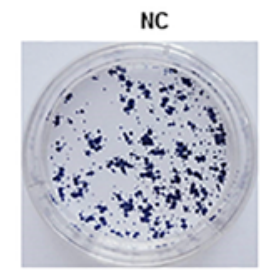

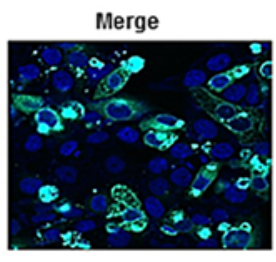

.
E

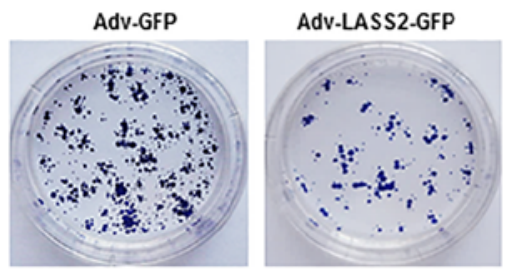

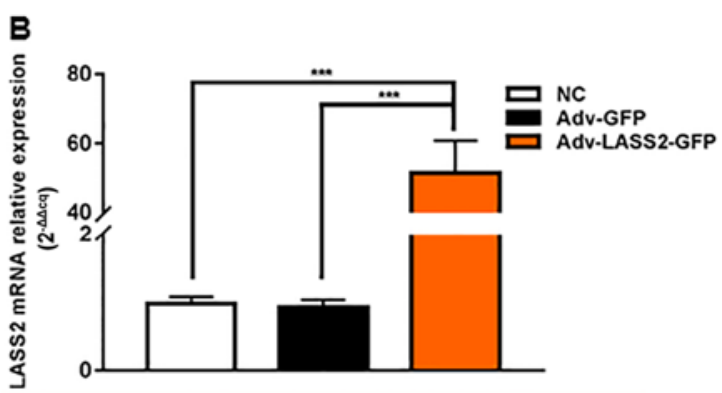
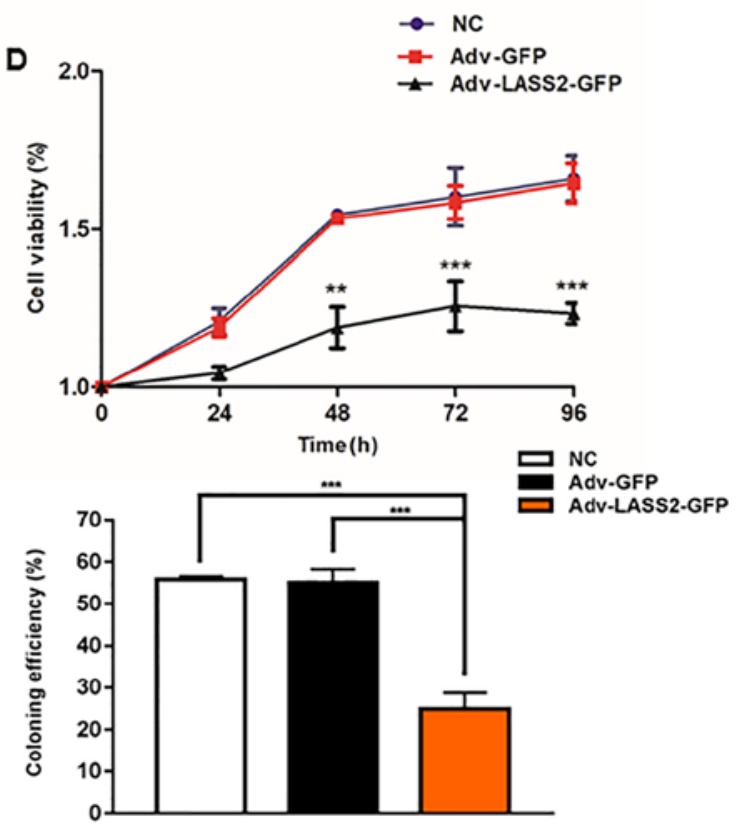

Figure 1. Overexpression of LASS2 inhibits HepG2 cells proliferation. (A) Subcellular localization of LASS2-GFP fusion protein by confocal laser scanning microscope (magnification, x200). Overexpression of LASS2 (B) mRNA and (C) protein in each group of the HepG2 cells was evidenced by RT-qPCR and western blot assays, respectively. RT-qPCR products of each group cells were analyzed by electrophoresis. GAPDH was used for normalization for the RT-qPCR assays and as a loading control for western blot analysis. (D) Results of Cell Counting Kit- 8 assays demonstrated the inhibited proliferation in LASS2-overexpression HepG2 cells. (E) LASS2 inhibited the cell growth in the semi-solid agar. Colony numbers of HepG2 cells transfected with Adv-LASS2-GFP were significantly reduced compared with those transfected with Adv-GFP or NC group. Data were presented as the mean \pm standard deviation $(\mathrm{n}=3) .{ }^{* *} \mathrm{P}<0.01$ and ${ }^{* * * *} \mathrm{P}<0.001$ as indicated or vs. Adv-GFP. RT-qPCR, reverse transcription-quantitative polymerase chain reaction; LASS2, LAG1 longevity assurance homolog 2; GFP, green fluorescent protein; NC, negative control.

were significantly reduced by $40.89 \pm 5.91$ and $46.95 \pm 6.43 \%$, respectively, in the cells transfected with Adv-LASS2-GFP compared with the control group (Fig. 2D). To investigate the mechanism for the effect of LASS2 on cyclin D1 expression, western blot analysis was performed to detect the changes in the expression of the CDK inhibitor p27. p27 is a negative regulator of cell cycle progression from $G_{1}$ to $S$ phase and is considered the most characteristic of CDK regulators. Furthermore, p27 inhibits cyclin-CDK complexes such as cyclin D1-CDK4 $(29,30)$. The present results revealed a significantly upregulated expression of p27 protein (1.46-fold) in the cells transfected with Adv-LASS2-GFP compared with the NC group (Fig. 2E).

LASS2 induces apoptosis in HepG2 cells by increasing ROS, reducing $\Delta \Psi_{m}$ and inducing $\left[\mathrm{Ca}^{2+}\right]_{i}$ overload. To confirm whether LASS2 overexpression induced apoptosis in HepG2 cells, the phosphatidylserine on the surface of apoptotic cells and nuclear DNA fragmentation during apoptosis was detected using Annexin V-APC/7-AAD and TUNEL assays, respectively. The proportion of Annexin V-APC and/or 7AAD-positive cells (Fig. 3A) and TUNEL-positive cells (Fig. 3B) was significantly higher in cells transfected with Adv-LASS2-GFP compared with cells transfected with Adv-GFP or NC cells.

To further investigate the mechanisms of LASS2-induced apoptosis, changes in intracellular ROS, $\Delta \Psi_{\mathrm{m}}$ and $\left[\mathrm{Ca}^{2+}\right]_{\mathrm{i}}$ were considered. The intracellular ROS level was determined by flow cytometry analysis with DHE staining. It was revealed that the overexpression of LASS2 significantly elicited ROS generation at $48 \mathrm{~h}$ post-transfection (Fig. 4A). To study whether LASS2 induced $\Delta \Psi_{\mathrm{m}}$ collapse in HepG2 cells, $\Delta \Psi_{\mathrm{m}}$ was measured using flow cytometry analysis with JC-1 dye. The LASS2-overexpressing HepG2 cells demonstrated a clear reduction of $\Delta \Psi_{\mathrm{m}}$ (Fig. 4B). Furthermore, the effect of LASS2 on $\left[\mathrm{Ca}^{2+}\right]_{\mathrm{i}}$ was determined by flow cytometry using Calbryte 630 AM fluorescence intensity. LASS2 overexpression promoted a significant increase of $\left[\mathrm{Ca}^{2+}\right]_{i}$ in HepG2 cells (Fig. 4C), leading to the disruption of intracellular calcium homeostasis. $\mathrm{Ca}^{2+}$-ATPase is the major active calcium transport protein in the maintenance of normal $\left[\mathrm{Ca}^{2+}\right]_{\mathrm{i}}$ in a variety of cell types (31). $\mathrm{Ca}^{2+}$-ATPase activity was determined using 
A

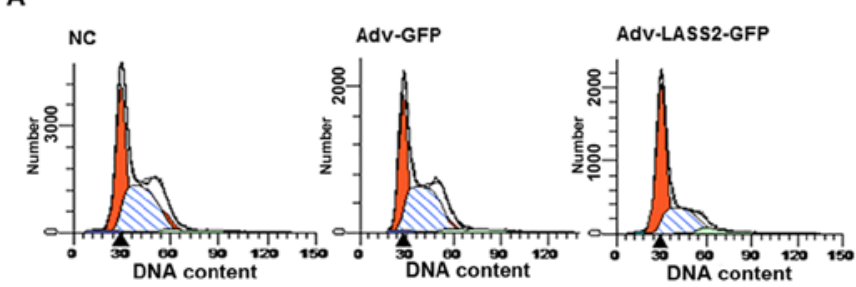

B

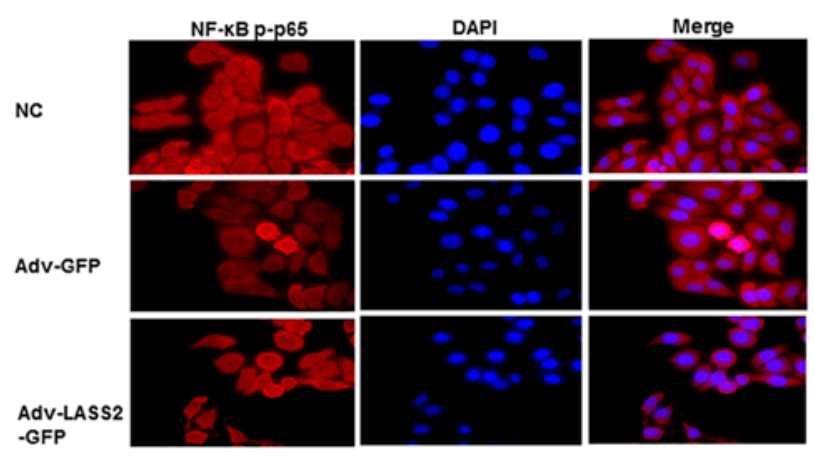

C
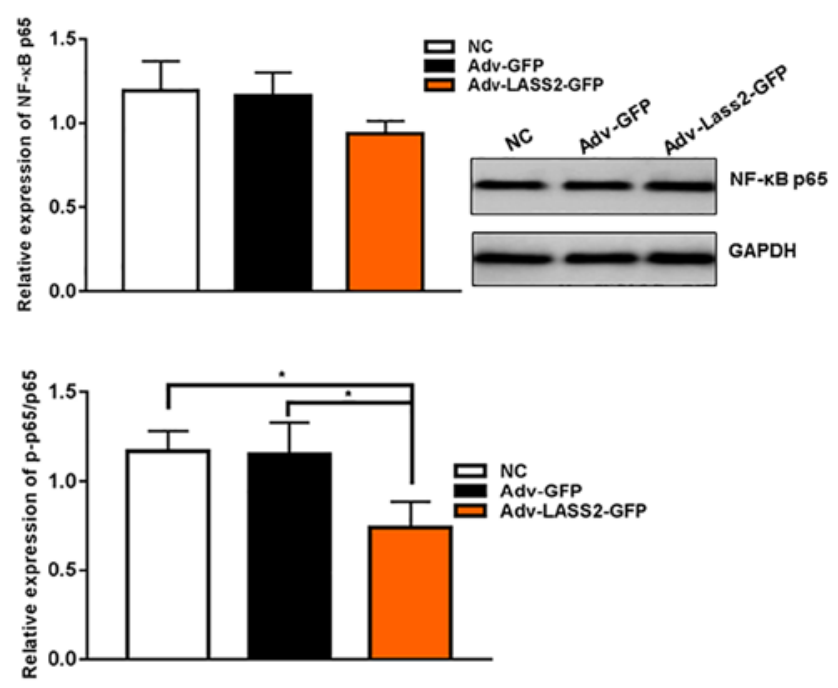

D

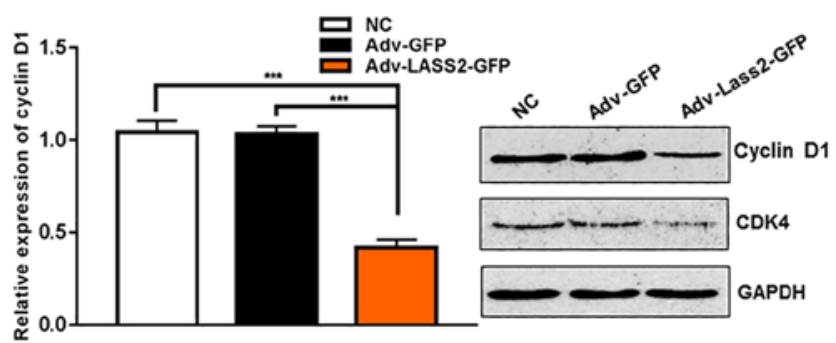

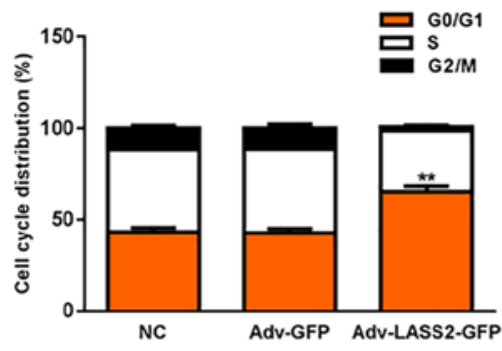

E

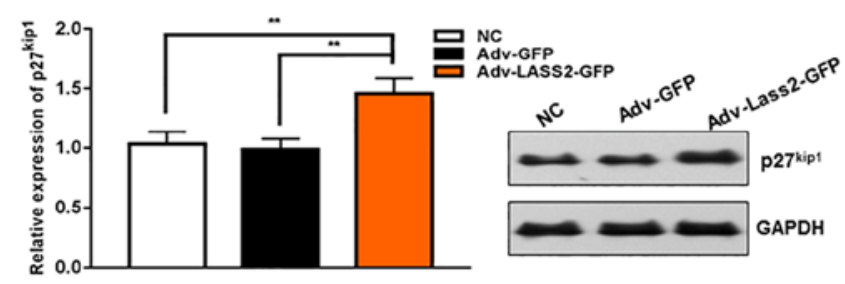

Figure 2. Overexpression of LASS2 induces $\mathrm{G}_{0} / \mathrm{G}_{1}$ cell cycle arrest via inhibiting NF- $\mathrm{kB}$ p65 activity, downregulates cyclin D1 and CDK4 expression and upregulates p27 expression. (A) Flow cytometry analysis revealed arrest of HepG2 cells at the $\mathrm{G}_{0} / \mathrm{G}_{1}$ phase in Adv-LASS2-GFP group following $48 \mathrm{~h}$ of transfection. (B) Immunofluorescence analysis demonstrated the cytoplasm of NF- $\mathrm{BB}$ p-p65 (red) in HepG2 cells (magnification, x200). The relative protein

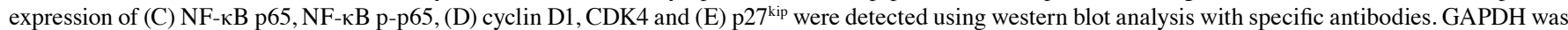
used as a loading control. ${ }^{*} \mathrm{P}<0.05,{ }^{* *} \mathrm{P}<0.01$ and ${ }^{* * *} \mathrm{P}<0.001$ as indicated or Adv-LASS2-GFP vs NC or Adv-GFP. DAPI, 4',6-diamidino-2-phenylindole; CKD4,

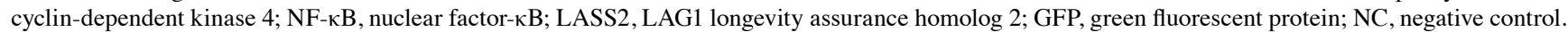

a colorimetric method by the inorganic phosphate content. A significantly reduced ATPase activity was detected in cells transfected with Adv-LASS2-GFP HepG2 cells compared with the Adv-GFP or NC cells (Fig. 4D). 
A
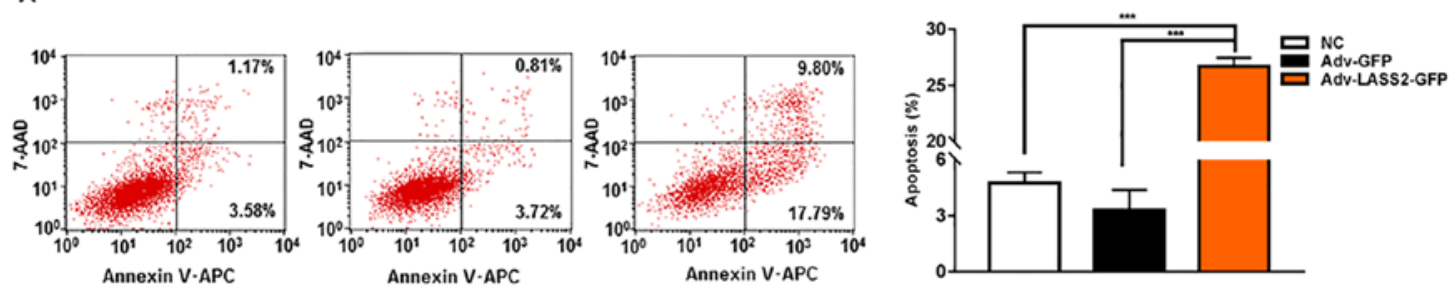

B
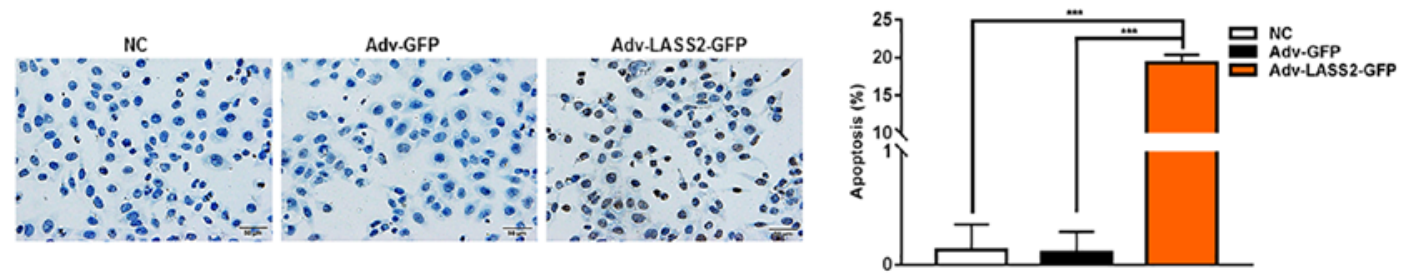

Figure 3. Overexpression of LASS2 promotes HepG2 cell apoptosis. (A) Apoptosis was detected using flow cytometry with Annexin V APC/7AAD in transfected HepG2 cells. (B) Apoptotic DNA fragmentation was detected using a biotin labeling dUTP TUNEL assay. Scale bar, $50 \mu \mathrm{m}$. TUNEL-positive cells in Adv-LASS2-GFP transfected cells were significantly increased. ${ }^{* * *} \mathrm{P}<0.001$ as indicated. APC, allophycocyanin; 7AAD, 7-amino-actinomycin D; TUNEL, terminal deoxynucleotidyl transferase dUTP nick end labeling; LASS2, LAG1 longevity assurance homolog 2; GFP, green fluorescent protein; NC, negative control.

A
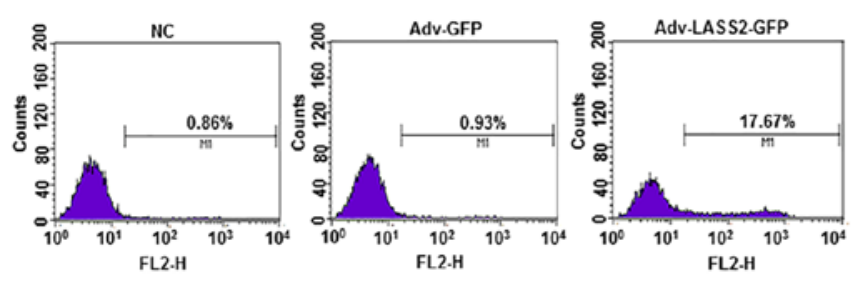

.
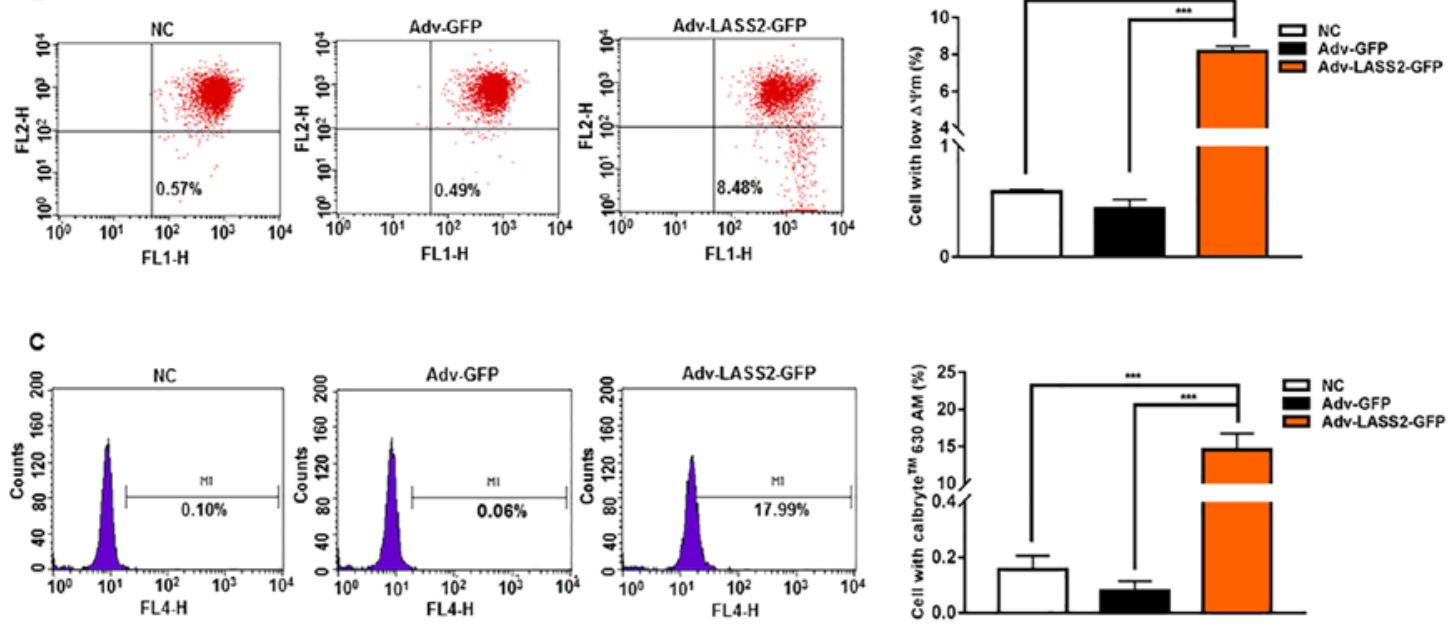

D

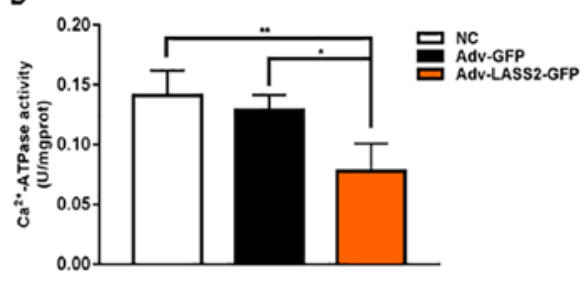

Figure 4. LASS2 induces apoptosis by increasing ROS, loss of $\Delta \Psi_{\mathrm{m}}$ and $\left[\mathrm{Ca}^{2+}\right]_{\mathrm{i}}$ overload. (A) Intracellular ROS level was determined using flow cytometry analysis with DHE staining. LASS2 elicited ROS generation at $48 \mathrm{~h}$ post-transfection with Adv-LASS2-GFP. (B) LASS2 induced $\Delta \Psi_{\mathrm{m}}$ collapse in HepG2 cells, mitochondrial membrane potential was measured by FCM analysis with JC-1 dye. (C) $\left[\mathrm{Ca}^{2+}\right]_{\mathrm{i}}$ in $\mathrm{HepG} 2$ cells was determined using flow cytometry and analyzed by Calbryte $630 \mathrm{AM}$ fluorescence intensity. (D) $\mathrm{Ca}^{2+}$-ATPase activity was determined by the content of inorganic phosphate using colorimetric method. ${ }^{*} \mathrm{P}<0.05,{ }^{* *} \mathrm{P}<0.01$ and ${ }^{* * * *} \mathrm{P}<0.001$ as indicated. $\Delta \Psi_{\mathrm{m}}$, mitochondrial membrane potential; ROS, Reactive oxygen species; LASS2, LAG1 longevity assurance homolog 2; GFP, green fluorescent protein; $\mathrm{NC}$, negative control; $\left[\mathrm{Ca}^{2+}\right]_{\mathrm{i}}$ intracellular $\mathrm{Ca}^{2+}$ concentration. 


\section{Discussion}

The occurrence and development of tumors is a complex process involving the gradual dysregulation of multiple signal networks. The malignant characteristics of tumor cells, such as unlimited proliferation, apoptosis resistance, invasion and migration, are associated with mitochondrial dysfunction (32). Until the present day, the majority of attention has focused on whether LASS2 can inhibit the growth of cells through repressing the activity of V-ATPase in various types of cancer cell, including HCC $(11,12)$, breast cancer (8) and prostate cancer cells (33). Huang et al (13) reported that overexpression of LASS2 induces mitochondrial apoptosis through downregulating mitochondrial membrane potential in BIU87 and J82 bladder cancer cells. A previous report indicated that LASS 2 overexpression induced cell cycle arrest at $G_{0} / G_{1}$ phase and induced apoptosis via a caspase-dependent mitochondrial pathway in HEK293 and 293 T cells (34). Whether LASS2 affects HB cell proliferation, apoptosis and cell cycle progression via the mitochondrial and associated NF-KB signaling pathways has not previously been identified. In the present study, the antiproliferative effect of LASS2 overexpression was validated, and it was identified that LASS2 overexpression induced apoptosis and cell cycle arrest in the $G_{0} / G_{1}$ phase in HepG2 HB cells. Tang et al (12) reported that overexpression of LASS2 could increase intracellular $\mathrm{H}^{+}$of $\mathrm{HCC}$ cells HCCLM3 via V-ATPase and induce cell apoptosis through the cytochrome $c$ mitochondrial pathway.

The mitochondria are an important site for the generation of ROS in eukaryotic cells, and intracellular calcium stores; at the same time, the mitochondria are the primary switch for intrinsic apoptosis $(35,36)$. ROS serve a second messenger role in the activation of transcription factors $(37,38)$, and not only directly damage biological macromolecules such as DNA (39), but also activate the apoptotic signaling pathway (40) and induce cell cycle arrest (41-43). The present results demonstrated that LASS2 overexpression increased the ROS concentration, and disrupted mitochondrial function as evidenced by the loss of $\Delta \Psi_{\mathrm{m}}$ and the induction of $\left[\mathrm{Ca}^{2+}\right]_{\mathrm{i}}$ overload, which has not been performed before. An increase in the ROS level could damage mitochondrial membranes and result in apoptosis through the oxidation of mitochondrial pores, thereby disrupting the $\Delta \Psi_{\mathrm{m}}(44,45)$. Calcium is a major signaling molecule in the regulation of various aspects of cell function, including the regulation of the cell cycle and apoptosis in a wide variety of cell types (46). Intracellular calcium homeostasis can be controlled by $\mathrm{Ca}^{2+}$-ATPase, calcium channels and calcium stores (47). To the best of our knowledge, the present study is the first to identify that LASS2 overexpression can inhibit the activity of $\mathrm{Ca}^{2+}$-ATPase; it was speculated that the inhibition of the calcium pumps promoted $\left[\mathrm{Ca}^{2+}\right]_{\mathrm{i}}$ overload, leading to the imbalance of intracellular calcium homeostasis and triggering a chain reaction leading to the initiation of apoptosis. The production of ROS is typically induced by mutation, hypoxia, inhibitors and the production of mitochondrial complexes I-IV $(48,49)$. Mutation, inhibitors and hypoxia induction were not considered in the present study. It was hypothesized that LASS2 may bind to ROS-producing target sites in the mitochondria to generate ROS. Further study is required to confirm this idea.
Numerous studies have indicated that intracellular ROS act as potent stimuli of NF- $\mathrm{kB}$ activation in various types of malignant tumor (50-52). However, whether the LASS2-induced ROS increase activates the NF- $\kappa B$ signaling pathway remains unclear. Thus, the association between ROS and the NF- $\mathrm{kB}$ p65 signaling pathway was explored. The western blot analysis results indicated that the phosphorylation of NF- $\mathrm{KB}$ p65 was significantly reduced subsequent to the upregulation of LASS2. The immunofluorescence staining and confocal microscopy results revealed that LASS2-elicited ROS generation may have impeded the translocation of NF- $\mathrm{kB}$ p-p65 to the nucleus. NF- $\mathrm{KB}$ is important in cell proliferation, apoptosis and cell cycle regulation to affect normal and malignant cell growth $(53,54)$. The activation of NF- $\kappa B$ affects $\mathrm{G}_{1} / \mathrm{S}$ and $\mathrm{G}_{2} / \mathrm{M}$ progression, and the CDK/CDK inhibitor system (55). Thus, the expression of cell cycle regulatory proteins, such as cyclin D1 and CDK4, and the cell cycle inhibitor p27 were examined. The data indicated that the overexpression of LASS2 reduced the relative protein expression of cyclin D1 and CDK4, and upregulated p27 protein expression. Other reports have indicated that NF- $\mathrm{KB}$ promotes $\mathrm{G}_{1}$-to-S-phase transition, potentially through cyclin D1 $(56,57)$. NF- $\kappa \mathrm{B}$ p 65 , but not $\mathrm{p} 50$, is a downstream mediator of arsenite-induced $\mathrm{p} 27^{\mathrm{kip} 1}$ protein upregulation in IKK $\beta^{-/}$cells (58), and $\mathrm{p} 27$ enhances NF- $\mathrm{KB}$ transactivation activity (54). p27 upregulation is particularly associated with $G_{0}$ quiescence (59) and the inhibition of cyclin D/CDK4 (60). Taken together, this suggests that LASS2 overexpression induced $\mathrm{G}_{0} / \mathrm{G}_{1}$ cell cycle arrest via the NF- $\mathrm{\kappa B}$ p65/p27/cyclin D1/CDK4 signaling pathway.

In conclusion, the results of the present study provide novel evidence to demonstrate that LASS2 is associated with mitochondrial apoptosis and NF- $\mathrm{kB}$ p65/p27/cyclin D1/CDK4 signaling pathway regulation in HepG2 HB cells. These results may form the theoretical basis for understanding $\mathrm{HB}$ tumorigenesis and provide a potential therapeutic target for $\mathrm{HB}$, although further study such as knockdown LASS2 in hepatocytes and other hepatoma cells is required to verify and explore more potential mechanisms of the LASS2 gene in vivo and in vitro.

\section{Acknowledgements}

Not applicable.

\section{Funding}

The present work was supported by grants from National Natural Science Foundation of China (grant no. 81460317), Nation High-tech R\&D Program of China (grant no. 2014AA022301), Guizhou Province Medical Science and Technology Project (grant nos. [2016]1174, LKZ [2011]32 and gzwjkj2015-1-015).

\section{Availability of data and materials}

The datasets analyzed during the current study are available from the corresponding author on reasonable request.

\section{Authors' contributions}

YY, XY, XM designed the study and drafted the manuscript. YY,XY, XO, JX performed the experiments. LL, GY analyzed, 
interpreted the data and critically revised the manuscript. YY and TZ performed the statistical analyses. All authors read and approved the manuscript and agree to be accountable for all aspects of the research in ensuring that the accuracy or integrity of any part of the work are appropriately investigated and resolved.

\section{Ethics approval and consent to participate}

Not applicable.

\section{Patient consent for publication}

Not applicable.

\section{Competing interests}

The authors declare that they have no competing interests.

\section{References}

1. Bosch FX, Ribes J, Díaz M and Cléries R: Primary liver cancer: Worldwide incidence and trends. Gastroenterology 127 (Suppl 1): S5-S16, 2004.

2. Bruix J, Han KH, Gores G, Llovet JM and Mazzaferro V: Liver cancer: Approaching a personalized care. J Hepatol 62 (Suppl): S144-S156, 2015.

3. Yan X and Qiu Y: Impact of current staging systems on treatment strategy for HBV-related hepatocellular carcinoma. Cancer Lett 379: 220-224, 2016.

4. Sia D, Villanueva A, Friedman SL and Llovet JM: Liver cancer cell of origin, molecular class, and effects on patient prognosis. Gastroenterology 152: 745-761, 2017.

5. Eichenmüller M, Gruner I, Hagl B, Häberle B, Müller-Höcker J, von Schweinitz D and Kappler R: Blocking the hedgehog pathway inhibits hepatoblastoma growth. Hepatology 49: 482-490, 2009.

6. Beck A, Trippel F, Wagner A, Joppien S, Felle M, Vokuhl C, Schwarzmayr T, Strom TM, von Schweinitz D, Längst G, et al: Overexpression of UHRF1 promotes silencing of tumor suppressor genes and predicts outcome in hepatoblastoma. Clin Epigenetics 10: 27, 2018.

7. Wu JF, Chang HH, Lu MY, Jou ST, Chang KC, Ni YH and Chang MH: Prognostic roles of pathology markers immunoexpression and clinical parameters in hepatoblastoma. J Biomed Sci 24: 62, 2017.

8. Mei F, You J, Liu B, Zhang M, Liu J, Zhang B and Pei F: LASS2/TMSG1 inhibits growth and invasion of breast cancer cell in vitro through regulation of vacuolar ATPase activity. Tumour Biol 36: 2831-2844, 2015.

9. Mizutani Y, Kihara A and Igarashi Y: Mammalian Lass6 and its related family members regulate synthesis of specific ceramides. Biochem J 390: 263-271, 2005.

10. Spassieva SD, Mullen TD, Townsend DM and Obeid LM: Disruption of ceramide synthesis by CerS2 down-regulation leads to autophagy and the unfolded protein response. Biochem J 424: 273-283, 2009 .

11. Gu D, Jin H, Jin G, Wang C, Wang N, Hu F, Luo Q, Chu W, Yao M and Qin W: The asialoglycoprotein receptor suppresses the metastasis of hepatocellular carcinoma via LASS2-mediated inhibition of V-ATPase activity. Cancer Lett 379: 107-116, 2016.

12. Tang N, Jin J, Deng Y, Ke RH, Shen QJ, Fan SH and Qin WX: [LASS2 interacts with V-ATPase and inhibits cell growth of hepatocellular carcinoma]. Sheng Li Xue Bao 62: 196-202, 2010 (In Chinese)

13. Huang L, Luan T, Chen Y, Bao X, Huang Y, Fu S, Wang H and Wang J: LASS2 regulates invasion and chemoresistance via ERK/Drp1 modulated mitochondrial dynamics in bladder cancer cells. J Cancer 9: 1017-1024, 2018.

14. Wang H, Zuo Y, Ding M, Ke C, Yan R, Zhan H, Liu J, Wang W, $\mathrm{Li} \mathrm{N}$ and Wang J: LASS2 inhibits growth and invasion of bladder cancer by regulating ATPase activity. Oncol Lett 13: 661-668, 2017.
15. Fan S, Niu Y, Tan N, Wu Z, Wang Y, You H, Ke R, Song J, Shen Q, Wang W, et al: LASS2 enhances chemosensitivity of breast cancer by counteracting acidic tumor microenvironment through inhibiting activity of V-ATPase proton pump. Oncogene 32: 1682-1690, 2013

16. Xu X, You J and Pei F: Silencing of a novel tumor metastasis suppressor gene LASS2/TMSG1 promotes invasion of prostate cancer cell in vitro through increase of vacuolar ATPase activity. J Cell Biochem 113: 2356-2363, 2012.

17. Ke RH, Wang Y, Mao Y, Zhang J and Xiong J: Decreased expression of LASS2 is associated with worse prognosis in meningiomas. J Neurooncol 118: 369-376, 2014.

18. Ruan H, Wang T, Yang C, Jin G, Gu D, Deng X, Wang C, Qin W and Jin $\mathrm{H}$ : Co-expression of LASS2 and TGF- $\beta 1$ predicts poor prognosis in hepatocellular carcinoma. Sci Rep 6: 32421, 2016.

19. López-Terrada D, Cheung SW, Finegold MJ and Knowles BB: Hep G2 is a hepatoblastoma-derived cell line. Hum Pathol 40: 1512-1515, 2009.

20. Zhang ZL, Liu GC, Peng L, Zhang C, Jia YM, Yang WH and Mao L: Effect of PAK1 gene silencing on proliferation and apoptosis in hepatocellular carcinoma cell lines MHCC97-H and HepG2 and cells in xenograft tumor. Gene Ther 25: 284-296, 2018.

21. Ceballos MP, Decándido G, Quiroga AD, Comanzo CG, Livore VI, Lorenzetti F, Lambertucci F, Chazarreta-Cifre L, Banchio C, Alvarez ML, et al: Inhibition of sirtuins 1 and 2 impairs cell survival and migration and modulates the expression of P-glycoprotein and MRP3 in hepatocellular carcinoma cell lines. Toxicol Lett 289: 63-74, 2018.

22. Dunham KR and Selman BR: Interactions of inorganic phosphate with spinach coupling factor 1. Effects on ATPase and ADP binding activities. J Biol Chem 256: 10044-10049, 1981.

23. Livak KJ and Schmittgen TD: Analysis of relative gene expression data using real-time quantitative PCR and the 2(-Delta Delta C(T)) Method. Methods 25: 402-408, 2001

24. Mankan AK, Lawless MW, Gray SG, Kelleher D and McManus R: NF-kappaB regulation: The nuclear response. J Cell Mol Med 13: 631-643, 2009.

25. PantanoC,ReynaertNL, vanderVliet A and Janssen-Heininger YM: Redox-sensitive kinases of the nuclear factor-kappaB signaling pathway. Antioxid Redox Signal 8: 1791-1806, 2006.

26. Zeng GZ, Wang Z, Zhao LM, Fan JT and Tan NH: NF-кB and JNK mediated apoptosis and G0/G1 arrest of HeLa cells induced by rubiarbonol $\mathrm{G}$, an arborinane-type triterpenoid from Rubia yunnanensis. J Ethnopharmacol 220: 220-227, 2018.

27. Li W, Zhi W, Zhao J, Yao Q, Liu F and Niu X: Cinnamaldehyde protects VSMCs against ox-LDL-induced proliferation and migration through $S$ arrest and inhibition of p38, JNK/MAPKs and NF- $\kappa$ B. Vascul Pharmacol 108: 57-66, 2018.

28. Ye D, Luo H, Lai Z, Zou L, Zhu L, Mao J, Jacob T, Ye W, Wang L and Chen L: ClC-3 chloride channel proteins regulate the cell cycle by up-regulating cyclin D1-CDK4/6 through suppressing p21/p27 expression in nasopharyngeal carcinoma cells. Sci Rep 6: 30276, 2016

29. James MK, Ray A, Leznova D and Blain SW: Differential modification of $\mathrm{p} 27^{\mathrm{Kipl}}$ controls its cyclin D-cdk4 inhibitory activity. Mol Cell Biol 28: 498-510, 2008.

30. Philipp-Staheli J, Payne SR and Kemp CJ: p27(Kip1): Regulation and function of a haploinsufficient tumor suppressor and its misregulation in cancer. Exp Cell Res 264: 148-168, 2001.

31. Caro AA, Evans KL and Cederbaum AI: CYP2E1 overexpression inhibits microsomal $\mathrm{Ca}^{2+}$-ATPase activity in HepG2 cells. Toxicology 255: 171-176, 2009.

32. Zong WX, Rabinowitz JD and White E: Mitochondria and Cancer. Mol Cell 61: 667-676, 2016.

33. Xu X, Liu B, Zou P, Zhang Y, You J and Pei F: Silencing of LASS2/TMSG1 enhances invasion and metastasis capacity of prostate cancer cell. J Cell Biochem 115: 731-743, 2014.

34. Su J, Yu W, Gong M, You J, Liu J and Zheng J: Overexpression of a novel tumor metastasis suppressor gene TMSG1/LASS2 induces apoptosis via a caspase-dependent mitochondrial pathway. J Cell Biochem 116: 1310-1317, 2015.

35. Hengartner MO: The biochemistry of apoptosis. Nature 407: 770-776, 2000.

36. Krammer PH, Kamiński M, Kiessling M and Gülow K: No life without death. Adv Cancer Res 97: 111-138, 2007.

37. Gupta AK, Ghosh K, Palit S, Barua J, Das PK and Ukil A: Leishmania donovani inhibits inflammasome-dependent macrophage activation by exploiting the negative regulatory proteins A20 and UCP2. FASEB J 31: 5087-5101, 2017. 
38. Ko EY, Cho SH, Kwon SH, Eom CY, Jeong MS, Lee W, Kim SY, Heo SJ, Ahn G, Lee KP, et al: The roles of NF- $\kappa B$ and ROS in regulation of pro-inflammatory mediators of inflammation induction in LPS-stimulated zebrafish embryos. Fish Shellfish Immunol 68: 525-529, 2017.

39. Pannunzio NR and Lieber MR: AID and reactive oxygen species can induce DNA breaks within human chromosomal translocation fragile zones. Mol Cell 68: 901-912.e3, 2017.

40. Zou Z, Chang H, Li H and Wang S: Induction of reactive oxygen species: An emerging approach for cancer therapy. Apoptosis 22 : 1321-1335, 2017.

41. Hsu YC, Huang TY and Chen MJ: Therapeutic ROS targeting of GADD45 $\gamma$ in the induction of G2/M arrest in primary human colorectal cancer cell lines by cucurbitacin E. Cell Death Dis 5: e1198, 2014.

42. Park WH: $\mathrm{H}_{2} \mathrm{O}_{2}$ inhibits the growth of human pulmonary fibroblast cells by inducing cell death, GSH depletion and G1 phase arrest. Mol Med Rep 7: 1235-1240, 2013.

43. Kim J, Kim SH, Johnson VJ and Sharma RP: Extracellular signal-regulated kinase-signaling-dependent G2/M arrest and cell death in murine macrophages by cadmium. Environ Toxicol Chem 24: 3069-3077, 2005.

44. KalghatgiS,Spina CS,Costello JC,Liesa M,Morones-RamirezJR, Slomovic S, Molina A, Shirihai OS and Collins JJ: Bactericidal antibiotics induce mitochondrial dysfunction and oxidative damage in Mammalian cells. Sci Transl Med 5: 192ra85, 2013.

45. Zhang S, Li T, Zhang L, Wang X, Dong H, Li L, Fu D, Li Y, $\mathrm{Zi} \mathrm{X}$, Liu HM, et al: A novel chalcone derivative S17 induces apoptosis through ROS dependent DR5 up-regulation in gastric cancer cells. Sci Rep 7: 9873, 2017.

46. Tiwari M, Prasad S, Shrivastav TG and Chaube SK: Calcium signaling during meiotic cell cycle regulation and apoptosis in mammalian oocytes. J Cell Physiol 232: 976-981, 2017.

47. Bagur R and Hajnóczky G: Intracellular $\mathrm{Ca}^{2+}$ sensing: Its role in calcium homeostasis and signaling. Mol Cell 66: 780-788, 2017.

48. Zorov DB, Juhaszova M and Sollott SJ: Mitochondrial reactive oxygen species (ROS) and ROS-induced ROS release. Physiol Rev 94: 909-950, 2014.

49. Hamanaka RB and Chandel NS: Mitochondrial reactive oxygen species regulate cellular signaling and dictate biological outcomes. Trends Biochem Sci 35: 505-513, 2010.
50. Moon DO, Kim MO, Lee JD, Choi YH and Kim GY: Rosmarinic acid sensitizes cell death through suppression of TNF-alpha-induced NF-kappaB activation and ROS generation in human leukemia U937 cells. Cancer Lett 288: 183-191, 2010.

51. Korn SH, Wouters EF, Vos N and Janssen-Heininger YM Cytokine-induced activation of nuclear factor-kappa B is inhibited by hydrogen peroxide through oxidative inactivation of IkappaB kinase. J Biol Chem 276: 35693-35700, 2001.

52. Jamaluddin M, Wang S, Boldogh I, Tian B and Brasier AR: TNF-alpha-induced NF-kappaB/RelA Ser(276) phosphorylation and enhanceosome formation is mediated by an ROS-dependent PKAc pathway. Cell Signal 19: 1419-1433, 2007.

53. Ge QL, Liu SH, Ai ZH, Tao MF, Ma L, Wen SY, Dai M, Liu F, Liu HS, Jiang RZ, et al: RelB/NF- $\kappa \mathrm{B}$ links cell cycle transition and apoptosis to endometrioid adenocarcinoma tumorigenesis. Cell Death Dis 7: e2402, 2016.

54. Wolff B and Naumann M: INK4 cell cycle inhibitors direct transcriptional inactivation of NF-kappaB. Oncogene 18: 2663-2666, 1999.

55. Cicenas J, Kalyan K, Sorokinas A, Jatulyte A, Valiunas D, Kaupinis A and Valius M: Highlights of the latest advances in research on CDK inhibitors. Cancers (Basel) 6: 2224-2242, 2014.

56. Hinz M, Krappmann D, Eichten A, Heder A, Scheidereit C and Strauss M: NF-kappaB function in growth control: Regulation of cyclin D1 expression and G0/G1-to-S-phase transition. Mol Cell Biol 19: 2690-2698, 1999.

57. Bera A, Ghosh-Choudhury N, Dey N, Das F, Kasinath BS, Abboud HE and Choudhury GG: NFאB-mediated cyclin D1 expression by microRNA-21 influences renal cancer cell proliferation. Cell Signal 25: 2575-2586, 2013.

58. Guo W, Liu J, Jian J, Li J, Wan Y and Huang C: IKK- $\beta / N F-\kappa B$ p65 mediates p27(Kip1) protein degradation in arsenite response. Biochem Biophys Res Commun 447: 563-568, 2014.

59. Poon RY, Toyoshima $\mathrm{H}$ and Hunter T: Redistribution of the CDK inhibitor p27 between different cyclin.CDK complexes in the mouse fibroblast cell cycle and in cells arrested with lovastatin or ultraviolet irradiation. Mol Biol Cell 6: 1197-1213, 1995.

60. Orlando S, Gallastegui E, Besson A, Abril G, Aligué R, Pujol MJ and Bachs O: p2 $7^{\mathrm{Kip} 1}$ and $\mathrm{p} 21^{\mathrm{Cip} 1}$ collaborate in the regulation of transcription by recruiting cyclin-Cdk complexes on the promoters of target genes. Nucleic Acids Res 43: 6860-6873, 2015. 